\title{
A Rare Case of Extensive Lichen Striatus
}

\section{Marahatta S', Khadka D K², Agarawal M ${ }^{3}$}

${ }^{1,2}$ Department of Dermatology \& Venereology, B. P. Koirala Institute of Health Sciences, Dharan, Nepal, ${ }^{3}$ Department of Pathology, B. P. Koirala Institute of Health Sciences, Dharan, Nepal.

\begin{abstract}
Lichen striatus is a rare dermatitis characterized by lichenoid papules arranged in a linear band along the Blaschko's line. Extremities are commonly affected sites. Sometimes, abdomen, buttocks and thighs may also be involved in a single extensive lesion. But, multiple lesions involving many Blaschko's lines are rare with only few publications till now. Hence, we are reporting a case of 14-year-old male presented with lichen striatus over left upper and lower extremities as well as left side of trunk.
\end{abstract}

Key words: Blaschko's line, Lichenoid, Lichen striatus

\section{Introduction}

ichen striatus (LS) is an asymptomatic skin Ldisease of unknown etiology. It is a self-limiting, inflammatory, linear dermatitis characterized by small, pink, lichenoid papules, which are discrete at first but rapidly coalesces, within few weeks or more to form a dull-red, slightly scaly, linear band along the line of Blaschko, typically on the extremities. ${ }^{1}$ The abdomen, buttocks and thighs may be involved in a single extensive lesion, but multiple lesions are rare with only a few cases having been reported in the published work so far till now. ${ }^{2,3}$

Here, we are going to report an interesting case of extensive LS that occurred unilaterally involving multiple Blaschko's lines over left upper limb, lower limb and trunk.

\section{Case Report}

A 14-year-old male presented to the dermatology department with appearance of multiple mildly itchy raised lesions over left side of the trunk, upper and lower extremities for last one month duration. On thorough cutaneous examination, he had multiple, skin colored to slightly erythematous as well as

\section{Address for correspondence}

Suchana Marahatta

B. P. Koirala Institute of Health Sciences, Dharan, Nepal

Tel: 025-525555 Ext 2015 (Office), 3009 (Res), Cell: 9862023236,

Fax: 977-25-520251)

E-mail: suchanamarahatta@yahoo.com violaceous, well to ill-defined papules, ranging in size from $0.1 \times 0.1 \mathrm{~mm}$ to $0.2 \times 0.3 \mathrm{~mm}$, round to oval in shape, some were discrete whereas some of them had coalesced to form irregular plaque. They were limited only over the left side of trunk (left lower abdomen), left upper and lower limbs; arranged linearly following the Blaschko's line. Fine scales were also noted on the surface of some of the papules.

A punch biopsy specimen taken from an erythematous papule of his left calf revealed parakeratosis, irregular acanthosis, spongiosis, vacuolar degeneration of the basal cell layer and exocytosis of lymphocytes. There were superficial perivascular inflammatory cell infiltrates comprising of lymphocytes, histiocytes and few melanophages. Focal areas in the papillary dermis showed dense infiltrate with extension into the lower portion of the epidermis.

Based on these clinical and histopathological bases, we made a final diagnosis of Lichen Striatus. He was then started on topical application of mometasone furoate cream and tacrolimus ointment with marginal efficacy.

\section{Discussion}

Several congenital and acquired dermatoses are known to occur along the Blaschko's lines. When a somatic mutation or chromosomal non-disjunction occurring during embryogenesis affects an epidermal progenitor cell, its daughter cells proliferate and migrate along Blaschko's lines. LS is one of the rare idiopathic, self limiting dermatosis mostly distributed along the Blaschko's lines. ${ }^{4}$ 
Generally it affects individuals from 4 months to 15 years of age. Clinically it is characterized by small, pink, lichenoid and pruritic papules, which are discrete initially but coalesce rapidly. It appears suddenly and extends within few weeks to form a dull-red, slightly scaly, linear band like lesions. Its width ranges usually from $2 \mathrm{~mm}$ to $2 \mathrm{~cm}$ and is often irregular. The lesion may be either only a few centimeters in length or may extend the entire length of the limb. ${ }^{1}$ The abdomen, buttocks and thighs may be involved in a single extensive lesions, but multiple lesions, either unilateral or bilateral, are rare with only a few cases having been reported in the published work so far till now. ${ }^{2,3}$

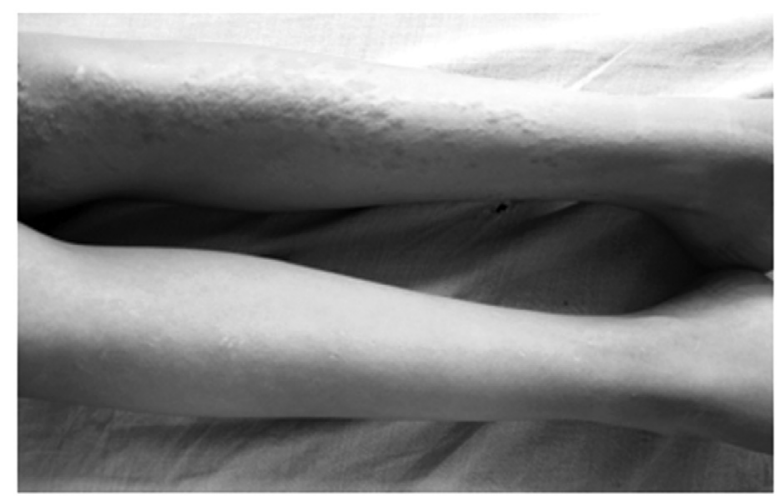

Figure 1: Lesions over anterior part of lower leg

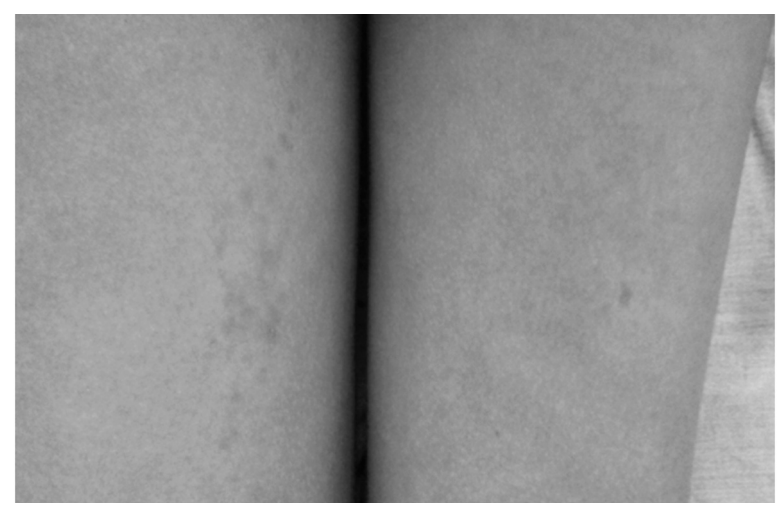

Figure 3: Lesions over left posterior thigh

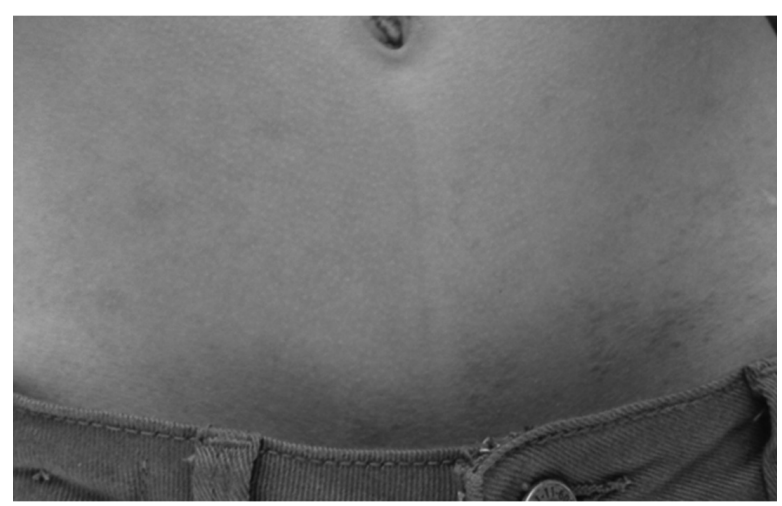

Figure 5: Lesions over anterior abdomen (left)
The diagnosis is usually made clinically, which is further supported by the appearance of the primary lesions and the distinctive pattern of evolution of the lesions. Its distribution along the Blaschko's lines and the age of the patient help to narrow down the differential diagnosis. But skin biopsy may be needed sometimes to rule out other lichenoid dermatoses in doubtful

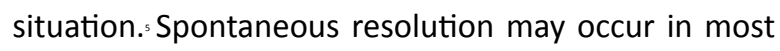
of the cases within 3-6 months. Since it is a self-limited condition, treatment is generally not necessary. But, Symptomatic control of pruritus with topical steroids may be necessary in some of the cases. ${ }^{1}$

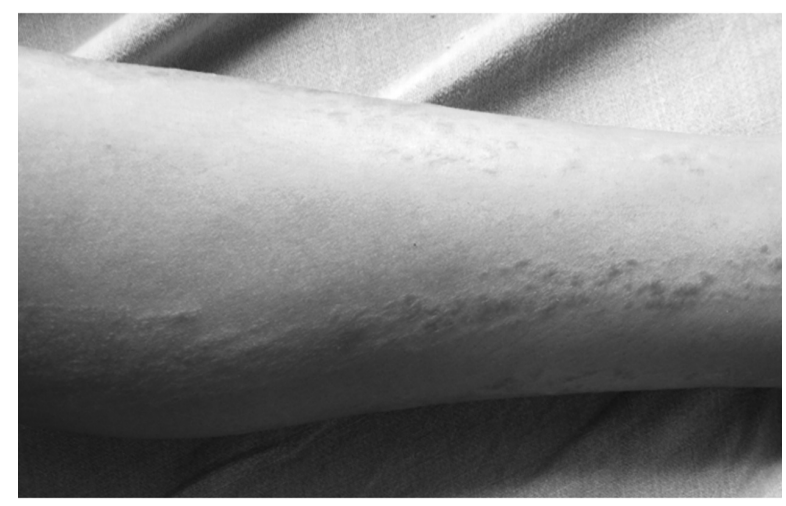

Figure 2: Lesions over postero-medial part of left lower leg

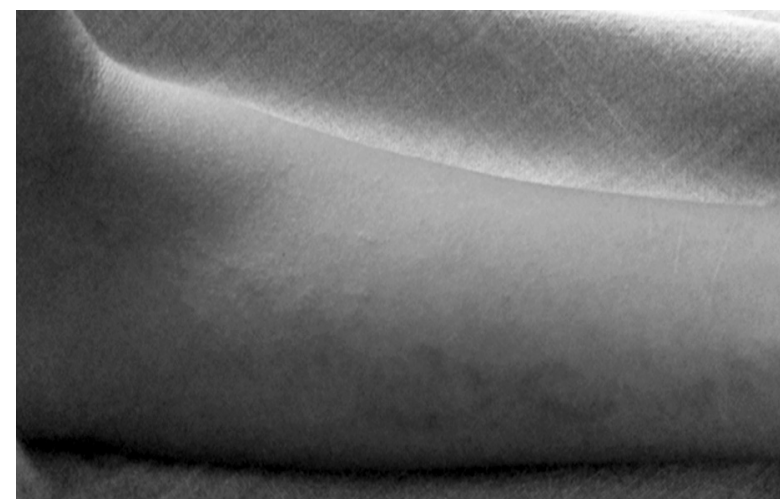

Figure 4: Lesions over medial forearm (left)

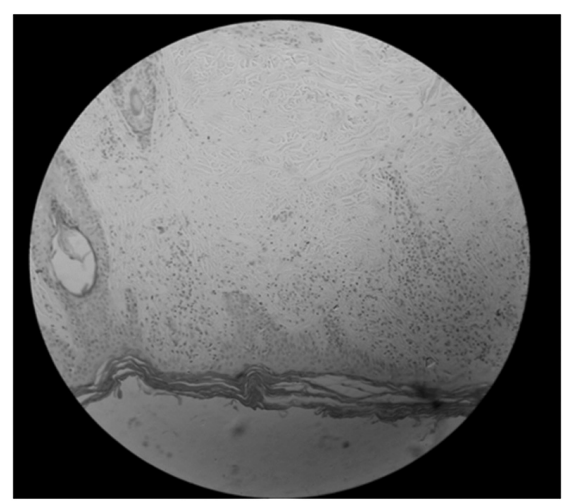

Figure 6: Histopathological picture (hematoxylineosin, original magnification 40X) 


\section{Conclusion}

Since there are only a few case reports on multiple lesions in lichen striatus, this case report is to extend our knowledge on lichen striatus with involvement of multiple Blaschko's line.

\section{Acknowledgement}

We are very much grateful to our patient. Similarly, we would like to express our sincere gratitude to
Head of the Dermatology department Prof Dr Sudha Agrawal for her constant encouragement, without which it would have been impossible. Our work will be incomplete without thanking Prof Dr Arpana Rijal for her constant support.

Consent for the Publication: Informed consent has been taken from the patient's mother for the publication

\section{References}

1. Jones JB. Eczema, Lichenification, Prurigo and Erythroderma. In: Burns T, Breathnach S, Cox N, Griffiths C (eds.) Rook's textbook of dermatology. Vol.1, Eigth edition, UK: WileyBlackwell; 2010. 23.41-23.42.

2. Kurokawa $M$, Kikuchi $H$, Ogata $K$, Setoyama M. Bilateral lichen striatus. J Dermatol 2004; 31: 129-32. http://dx.doi. org/10.1111/j.1346-8138.2004.tb00522.x

3. Sato $H$, Shirai A, Asahina A. Case of lichen striatus presenting with multiple lesions along Blaschko's lines. The Japanese J of Dermatology

2012; 122: 802-4. http://dx.doi.org/10.1111/ j.1346-8138.2011.01427.x

4. Keegan BR, Kamino $H$, Fangman $W$, Shin $H T$, Orlow SJ, Schaffer JV. "Pediatric blaschkitis": expanding the spectrum of childhood acquired Blaschko-linear dermatoses. Pediatr Dermatol 2007; 24: 621-7. http://dx.doi.org/10.1111/ j.1525-1470.2007.00550.x

5. Youssef SM, Teng JM: Effective topical combination therapy for treatment of lichen striatus in children. a case series and review. J Drugs Dermatol 2012; 11: 872-5. 